\title{
The influence of social percolation in improving fundraising strategies of charity organizations
}

\author{
Emi Trepci \\ Wirtschaftsuniversität Wien \\ Rainer Hasenauer \\ Marketing Management Institute \\ Wirtschaftsuniversität Wien \\ Hi-Tech Center
}

This paper aims to take a deeper look into the influence that social network factors, specifically word of mouth, have on donations decisions. It assumes that people tend to take donation decisions more often when there is some "social pressure" towards them, rather that when they are faced with the same case that requires donation, but privately. The whole study is going to be conducted in the focus of the social percolation theory. This study is expected to be of help, based on an innovative technology, to all the donations initiators including private and public charity institutions.

\section{INTRODUCTION}

This study was initially inspired by the idea of improving the ways charity organizations do fundraising. Although their intention is totally different to profit oriented companies, their campaigns and ways to attract potential donators are pretty much the same.

The whole study is done in the scope of word of mouth power. Donating and giving money for charity is an action which is driven directly by people's ethical emotions toward different cases. That is why people are very sensitive when it comes to cases of big problems for which everyone is talking about.

In this way, we are testing the power of word of mouth itself. The word of mouth power and the adoption of innovation among a network of people is studied for a long time now from Social Percolation.

Social percolation studies and explains the diffusion of information for a particular innovation among a group of people and the adoption potential of this innovation. Even though percolation is studied and applied in marketing about innovations such as products and services it can be applied in any kind of innovation which can be spread through word of mouth. Any content of word of mouth which can be communicated as an information entity might be subject of not only innovation, but also social percolation. In this way this study will also deepen the knowledge about social percolation and its possibilities of being applied in such a case where people are expected to be convinced in donation for a charity occasion (Macy \& Michael, 1991; Rogers \& Everet, 1993). 
The study is done in collaboration with Doctors Without Borders (Ärzte Ohne Grenzen, 2017) Austria. They offered their collaboration in regards to all information needed to build this study. Their assistance consists specifically in information regarding different fundraising methods they and other charity organizations have used in years.

As already mentioned above the main aim of this study is to offer a new perspective which would help organizations reach more potential donators in an effective way.

\section{SOCIAL PERCOLATION}

"Diffusion is the movement of a fluid from an area of higher concentration to an area of lower concentration. Diffusion is a result of the kinetic properties of particles of matter. The particles will mix until they are evenly distributed" (Diffusion Definition in Chemistry, 2018).

Despite physics, the diffusion concept and diffusion models have been studied for long in the social sciences. Social percolation itself is explained and applied in the basis of the concept of diffusion (Delre, Jager, Bijmolt \& Janssen, 2007; Dodds \& Watts, 2005; Goldenberg, Libai, Solomon, Jan \& Stauffer, 2000). Most of the diffusion innovation models are structured and explained according to the Bass model (Bearden, William \& Etzel, 1982; Bearden, William \& Rose, 1990; Delre, Jager, Bijmolt \& Janssen, 2010).

Traditionally percolation is defined as a random movement in a non-random medium. When applying this concept from physics in the economic context the most adequate definition is: " $a$ deterministic movement in a random medium" (Wierman \& John, 1982).

\section{Percolation in Social/Economic/Marketing Perspective}

In a social percolation model there are people who are connected by social relations to other people belonging in the same subgroup of social network (Solomon et al., 2000).

It is assumed that every agent is symmetrically connected to other neighbors. In such a model, nodes placed in a two dimensional lattice are represented by people called agents. Agents in social percolation models are always faced with a binary choice. It consists in whether to adopt or not an innovation, whether to purchase or not a product etc. People may get the information about an innovation from a neighbor, but getting the information does not always consist in adoption. After being exposed with the innovation, agents decide whether to adopt or not adopt. When they adopt, the node/agent is perceived to be an active node/agent. The medium through which the agents in this model take the information is the word of mouth (Macy et al., 1991; Rogers et al,. 1993). The word of mouth flows through the network giving information about the innovation to everyone who has access to it. In social percolation models, the minimal requirement indicates the agent's preferences. It is a value for money index or just a specific level of requirement which serves as a comparison standard. People compare it with the quality of the innovation in order to decide whether to adopt or not (Silverberg, Gerald \& Verspagen, 2005).

\section{Conditions that Need to be Fulfilled}

A model needs to fulfill the ongoing conditions to be considered a social percolation model:

- Agents should be positioned in a social network. A social network is a graph where the nodes represent the agents. Between these agents always exists a certain link which allows the information to flow among them.

- Information can be passed from one agent to another, only if there is a link between them.

- The choice of the earlier adopters is always random.

- Choices are binary, which means that the agents decide to adopt the innovation or not. There is no other solution in between.

- The population of agents is heterogeneous. 
- Heterogeneity of agents including the number of nodes, clustering and distribution of the links determines speed and degree of the information diffusion (Rahmandad, Hazhir \& Sterman, 2008). For example, innovations are more likely to be adopted by more customers when agents are positioned in a scale free network than when they are positioned in a regular lattice (Delre, Jager \& Janssen, 2009). The diffusion and percolation in random networks depends more in the connectivity of the network than the number of early adopters/nodes (Watts, 2002).

- The spread of information and the social influence are two separated phenomena. An agent may get the information about an innovation from other agents, but still decide not to adopt it. Then at a further point of the simulation, when also other agents have adopted, he also decides to do so. So even though the information is transmitted through the word of mouth, it is still up to the agents to decide whether to adopt or not and when to do so (Delre et al., 2010; Mort, 1991).

\section{The Structure of a Percolation Model}

Most of the types of normal networks of agents/people take place in the structure of a regular lattice. There are different types of lattices, such as rectangular, triangular or honeycomb. In this study we will focus on two dimensional regular lattice. The dimensions can vary such as $400 \times 400$ cell lattice or 50x50 cell lattice, etc (Stauffer, Adler \& Aharony, 1994). Within this lattice, the cells are grouped in clusters. These cells have two different states. They are either active, named as "1", or not active, named as " 0 ". When the cell is active, it means it has adopted the innovation. When it is not active, it means it has not adopted the innovation. Each cell has a specific probability of turning into an active cell, meaning that it depends from this probability how many cells will be activated. When a cluster of cells, which means activated cells, is big enough to touch at least one cell per each column and each row of the cluster, it means that percolation has occurred. Percolation takes place if there is a path (sequence of connected nodes) between the starting node (North border or East Border) in the lattice and a node on the opposite border of the lattice (South border or west border) (Bruyn \& Lilien, 2008; Dodds \& Watts, 2005).

\section{Utility Factor}

According to agent based models, people choose to adopt an innovation according to the perceived utility they would get by doing this adoption. The utility $\left(\mathrm{U}_{\mathrm{ij}}\right)$ includes both the individual preference and social preferences.

First of all, when an agent is involved in a WOM process the probability for him/her to adopt is:

$a_{i, j}=P\left(U_{i, j} \geq U_{i, M I N}\right)$

$\mathrm{U}_{\mathrm{i}, \mathrm{j}}$ is the utility that the agent $i$ has when he/she adopts the innovation $j$. Agent's $i$ minimum utility requirement is $U_{i, \text { MIN }}$ (Delre et al., 2007).

The utility agent consists on:

$U_{i, j}=\beta_{j} * x_{i}+\left(1-\beta_{j}\right) * y_{i}$

( $\beta$ can only take within the closed interval $[0,1]$ ) (Delre et al,. 2007)

$\mathrm{x}_{\mathrm{i}}$ represents the local social influence whereas $\mathrm{y}_{\mathrm{i}}$ represents the individual preference of $i$ 's personal network (Delre et al., 2007). $\beta_{\mathrm{j}}$ weighs these two components and represents the amount of the social influence effect for the $j$ product. The higher $\beta_{\mathrm{j}}$ is, the more socially susceptible is the agent. In this case agents highly depend on what their neighbors do. The other way around happens when $\beta_{\mathrm{j}}$ is low. The lower $\beta_{\mathrm{j}}$, the more individualistic the agent is and his/her decisions are not influenced from his/her neighbors (Delre et al., 2010). 


\section{RESEARCH SETTING/QUESTION/DESIGN}

In this study the innovation is: donating for a charity cause. The behavior and effect of word of mouth is going to be explained through a percolation model. Social percolation is going to be the focus from which the assumptions are being studied. This study is also contributing in providing a deeper knowledge in the immense field of social percolation.

The main research question is:

"Will the social percolation model explain the behavior of potential donators in this specific social network?"

It is going to be tested whether some assumed factors will influence the behavior of people toward donating for a specific presented case. These factors are perceived to have their influence in convincing people donate after being presented to the case by one of their close friends/relatives.

The target group of this experiment are people living in Austria, above the age of 25 and that have a full time job.

\section{Assumptions of the Study}

- People's behavior toward a charity case differs according to the source from which they get the information from.

- The trustworthiness toward the source plays a big role in people's donation behavior.

- The level of education influences people's decision whether to donate or not donate.

- Age has a certain influences toward donating.

- Having a full-time job vs. not having it influences attitude toward donating.

- The social network can also have some sort of social pressure in convincing people donate.

- The target group of this study, people living in Austria, both Austrians and not Austrians, tend to not be willing to publically speak about their donation actions.

\section{The Questionnaire}

This study is based on quantitative research methods. The data collecting is done by the assistance of a questionnaire. This questionnaire is distributed online among the right target group.

The people taking the questionnaire are presented first with a charity case. The case is provided from Doctors Without Borders. The case aims to raise funds about the critical actual state in South Sudan. The whole country is characterized from deep poverty and absence of the basic healthcare conditions. In building the case it is used the concept of Identified Victim Effect (IVE). People seem to be more willing to help others when the problem has a "face" (Erlandsson, Arvid, Västfjäll, Sundfelt \& Slovic, 2016).

In our case we present the story of two little brothers. One of them had serious health issues from the malnourishment and his older brother takes care of him until he recovers, even though he is himself a child. In this way the case gives a picture of the problems that people who live in that country have. It shows how life is seriously threatened from malnourishment and bad healthcare services. It also shows how young children learn to take care of themselves in an early age because their parents have no power and are not able of doing that.

\section{THE MODEL}

The model used is a social percolation model because it fulfills all the social percolation conditions which are mentioned above.

The study "User acceptance of information technology" from Vankatesh and Smith has given a great contribution in building this model. Vankatesh and Smith give a great overview and unification of eight different diffusion models involving almost all potential factors that can be used. UTAUT (Unified 
Theory of Acceptance and Use of Technology) was tested and proved to outperform all eight models with and $\mathrm{R}^{2}$ of $70 \%$. Our model also will more or less be completely based on UTAUT.

In the theories of Individual Acceptance is worth mentioning the Theory of Planned Behavior (TPB), Technology Acceptance Model (TAM), Motivational Model (MM), The Theory of Reasoned Action (TRA), Innovation Diffusion Theory (Venkatesh, Viswanath, Morris, Davis B \& Davis D, 2003).

In the case of innovative products/technologies is widely used the model called TAM (Technology Acceptance model). The factors taken in consideration are: Perceived Usefulness, Perceived Ease of Use etc. Although in most of the studies these factors are the most frequently used, the ones in our model are not valid.

The Figure 1 below shows the main outcome of the UTAUT model.

FIGURE 1

\section{UTAUT MODEL}

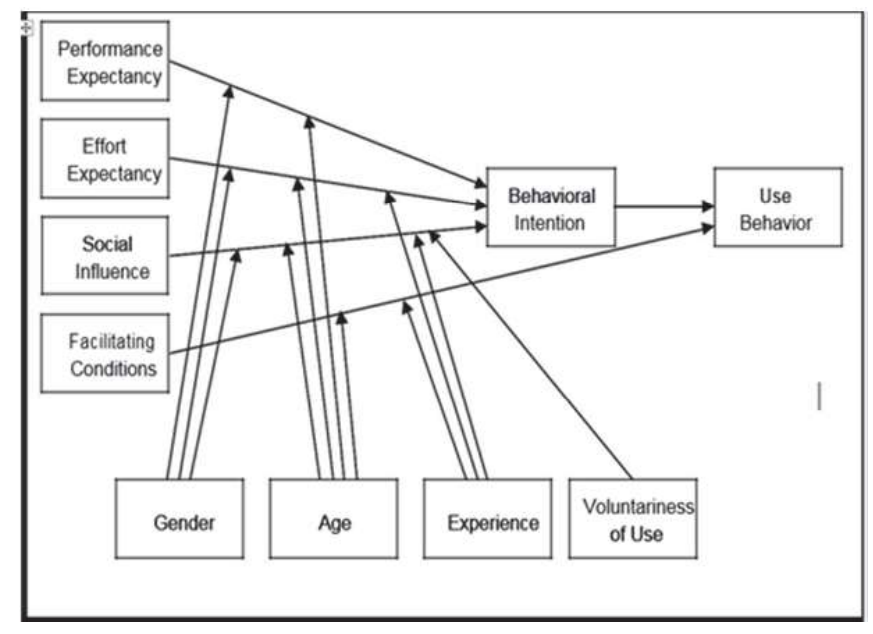

The eight boxes show the most determining factors that affect acceptance and user behavior. As we can see from the figure 1, Social Influence is being defined explicitly by gender, age, experience and voluntariness of use. On the other hand Performance Expectancy, Effort Expectancy and Social Influence itself are all together influencing the behavioral intention. In the end Facilitation Conditions result in influencing the Use Behavior (Venkatesh et al; 2003).

- Performance expectancy is the level of belief people have that using a specific system is going to help them have a great quality and advantages in the job performance (Venkatesh et al; 2003).

- Effort expectancy has to do with the ease of use that is perceived to associate the use of the system (Venkatesh et al; 2003).

- Social influence is the amount with which a person perceives as important the fact of whether the members of his social network use the new system (Venkatesh et al; 2003).

- Facilitating conditions represent the degree with which a person believes that the reason why a technical/organizational infrastructure exists is to back up the use of the system (Venkatesh et al; 2003).

From what is mentioned above, we can conclude that there can be factors used specifically for our model. When it comes to Individual Acceptance, the right model to use should be: Motivational Model (MM) which has two main factors: Extrinsic Motivation and Intrinsic Motivation.

"Extrinsic Motivation: The perception that users will want to perform an activity because it is perceived to be instrumental in achieving valued outcomes that are distinct from the activity itself, such as improved job performance, pay, or promotions" (Davis, Fred, Richard \& Warshaw, 1992). 
"Intrinsic Motivation: The perception that users will want to perform an activity for no apparent reinforcement other than the process of performing the activity per se." (Davis et al,. 1992).

In this way in our model we will use as individual acceptance:

$\mathrm{Yi}=\mathrm{f}($ extrinsic motivation; intrinsic motivation)

As for extrinsic motivation there will be included factors that have to do with how people think the society will perceive them after donating. Although, the intrinsic motivation has to do only with individualistic feeling of the donation action. To be more specific:

- Donation would make me feel good for being perceived from the society as a philanthropist.

- Donation would make me feel part of a group that consider themselves as philanthropists.

- Donation would make me feel good because of being part of a group who is doing something meaningful.

- Donation would make me feel good for having my own influence in helping people solve vital problems.

As for social acceptance we will use:

$\mathrm{Xi}=\mathrm{f}($ Education; Trustworthiness toward the channel)

As shown above, the individual acceptance is different from what is used in models of innovative technologies, whereas for the social acceptance same factors can be used for both different kind of innovation. In this way we can say that status, education and trustworthiness are factors that influence highly people's decisions independently for what kind of decision we are talking about.

\section{RESULTS}

\section{General Findings}

As previously mentioned the questionnaire was distributed online. Here are some general findings:

- Number of respondents: 126.

- Age: $70.6 \%$ of the respondents are over 24 years old. The average age is 31.5 years old. The age ranges from 17-96 years old.

- Place of living: $92 \%$ of the respondents live in Austria. The rest of the countries where $8 \%$ of the respondents live are: USA, Canada, Italy, Netherlands, Croatia and Albania.

- Nationality: $71 \%$ of the respondents declared to have an Austrian nationality. The rest of the nationalities varies in: Albania, Australia, Bosnia-Herzegovina, Canada, China, Croatia, Germany, Greece, Hungary, Iran, Italy, Korea, Poland and Slovakia.

- Education: $48 \%$ of our respondents are graduates and $16.7 \%$ of them are postgraduates, which means that more or less we have to do with a highly educated group of respondents.

- Full time job/No full time job: $53 \%$ of our respondents said that they have a full time job, whereas $44.4 \%$ do not have a full time job.

Answers regarding to different scenarios (different sources of information):

- Source of Information: close friends/relatives. $42 \%$ of people would decide to donate when asked to do so from their close friend/relative. Considering $42 \%$ of the respondents to be quite high, we could say that one of our assumptions is fulfilled since a lot of people accept that would be affected to behave in a certain way from close people in their social network.

- Source of information: shared post in social media from a public figure. When presented about this case from a shared post in social media $34.9 \%$ of people indicated that they would decide to donate about this case when presented by a shared post in social 
media. From them, 23\% indicated that they would not only donate, but also share this post in their account.

- Source of information: e-mail from the organization.

In the case of the e-mail respondents indicated that only $10.3 \%$ of them would decide to donate.

- Source of information: TV ad.

In the case of TV ad there was the lowest percentage of people that would decide to donate according to our data. They were only $6.3 \%$ of 126 respondents.

To sum up, this part of the different scenarios proved to be as it was expected to happen. People show higher willingness to donate when a close person tells them to do so and also when a public figure virtually "asks" them to donate. On the other hand, when the classical ways such as e-mail and TV ads are presented, people do not show high will in accepting to donate.

\section{Communication of personal donations}

Perceived Personal Influence

People were asked about their perceived personal influence among their social network. The alternatives were: $1-3 ; 3-6 ; 6-9$ and over 9 people. Surprisingly the results were not so optimistic. The average number was around 2 people per respondent. This means that most of people do not perceive themselves to have a big influence in the behavior of people close to them.

\section{People Willingness to Publically Show their Humanitarian Acts}

In this group of question it is tested the assumption that people living in Austria are not comfortable when it comes to publically speaking about their donations, the amount donated and in asking other people to donate money because they also did so. The average answers for these questions are 5 or 6 in a scale from 1 to 10 . This is quite neutral and we do not see a strong positive or negative tendency. Although it is interesting to interpret the difference between the answers who had an average of 5 and those having an average of 6 . Even though it is not a big difference, still it can be significant. If is noticed, both questions which had slightly higher averages compared to others asked people if you would be willing to "participate" in charity events or whether they would be willing to "ask people" in their social network to donate about a case. On the other hand, questions that asked people whether they would be willing to "publically speak" about their donations and whether they would be "initiators of a charity" event had slightly lower average in answering. This means people would be willing to be a part of a donation campaign and try to have their impact, but when it comes to take initiatives in their own, or to speak in public about the cause they maybe take a step backwards since they don't want to socially expose themselves.

\section{Perceived External Influence in the Behavior of Respondents}

People indicated that they would be highly influenced to decide to donate if a lot of people in their social network are donating and are asking them to do the same. This is highly positive as well for our assumptions. It indicates that word of mouth that comes from close friends or relatives tends to have a high effect in people's actions and decisions.

From the results we come into a conclusion that people usually have trouble in trusting e-mails/mails that they receive from different organizations. This leads to ignoring these kinds of e-mails and not generating any discussion among people. In the perspective of charity organizations, this means that these e-mails will probably not generate donation of money as they were expected to.

\section{Past Donating History}

Almost $80 \%$ of the people indicated that they have already donated at least once in their life. When asked about how they got inspired to donate, it was surprising to see that in $31 \%$ of the cases people said they didn't get inspired from the organization interested about the case. So they didn't get the 
information through one of the ways the charity organizations used, but in another way, and then they searched for a way to donate.

\section{Factors Influencing the Decision of Donating}

As shown from the assumptions, factors that are perceived to be influencing the people's decision in whether to donate or not are as it follows:

- Education level (e)

- Trustworthiness (b) I always question the reliability of the organizations sending me emails/mails for donation causes)

- Extrinsic motivation:

1. Good for being perceived from the society as a philanthropist (a)

2. Good for being part of a group that identify themselves as philanthropist (c)

3. Good for being part of a group of people who are doing something meaningful (f)

- Intrinsic Motivation

Good for having own influence in helping people solve vital problems (d)

This is one of the most important analysis of the study. All the factors listed above represent the Independent Variables (IV) of the analysis. We want to test how much these factors influence the decision of donating when presented from a friend/relative. In this way the Dependent Variable (DV) has two options: yes/no. Since the dependent variable is binary, the right statistical test to use is the binary logistic regression. The binary logistic regression tests the influence that the factors have in increasing or decreasing the odds that people would choose to donate.

$\boldsymbol{H}_{0}$ : The model adequately fits the data.

$\mathrm{H}_{1}$ : The model does not fit the data.

TABLE I

HOSMER AND LEMESHOW TEST

\begin{tabular}{|c|c|c|c|}
\hline Step & Chi-square & df & Sig. \\
\hline 1 & 6.708 & 7 & $\mathbf{4 6 0}$ \\
\hline
\end{tabular}

From the Hosmer and Lemeshow Test we see that $p>0.05$ which means that the results are significant and that the $\mathrm{H}_{0}$ is approved. The model adequately fits the data.

TABLE 2

CLASSIFICATION TABLE

\begin{tabular}{|c|c|c|c|c|c|}
\hline & & & Prec & & \\
\hline & & & Ado & probability & \\
\hline & Observed & & No & Yes & Percentage Correct \\
\hline Step 1 & Adoption & No & 57 & 14 & 80.3 \\
\hline & probability & Yes & 25 & 29 & 53.7 \\
\hline & Overall Per & & & & 68.8 \\
\hline
\end{tabular}


The classification table shows that the predicting percentage of the model is nearly $70 \%$ which is not a perfect prediction percentage, but it is still significant.

TABLE 3

\begin{tabular}{|c|c|c|c|}
\hline \multicolumn{2}{|c|}{$\begin{array}{l}\text { Variables in the Binary Logistic } \\
\text { Regression }\end{array}$} & \multirow{2}{*}{\begin{tabular}{|l|}
$\mathrm{B}$ \\
1.220 \\
\end{tabular}} & \multirow{2}{*}{\begin{tabular}{|l}
$\operatorname{Exp}(\mathrm{B})$ \\
3.388 \\
\end{tabular}} \\
\hline \multirow[t]{7}{*}{ Step 1a } & c/Extrinsic motivation & & \\
\hline & a/Extrinsic motivation & .695 & 2.004 \\
\hline & f/Extrinsic motivation & .392 & 1.480 \\
\hline & e/Education & .157 & 1.170 \\
\hline & $\mathrm{d} /$ Intrinsic Motivation & .250 & 1.284 \\
\hline & b/Trustworthiness & .243 & 1.274 \\
\hline & Constant & -3.525 & 0.029 \\
\hline
\end{tabular}

Binary Logistic Regression:

$\log (p / p-1)=0.029+2.004 a+1.274 b+3.388 c+1.284 d+1.170 e+1.480 f$

From the regression model we can derive the utility factor which fits to our model.

$\mathrm{Yi}=\mathrm{f}$ (extrinsic motivation; intrinsic motivation)

$X i=f($ trustworthiness; education level)

Utility factor $=0.029+\beta i(1.170 *$ education $+1.274 *$ trustworthiness $)+(1-\beta i)(3.388 *$ extrinsic motivation $+2.004 *$ extrinsic motivation $+1.480 *$ extrinsic motivation $+1.284 *$ intrinsic motivation)

If we want to make an interpretation of the factors would be like this one:

"With one extra level of education the odds for one person to donate increase with a factor of 1.170 (the same logic would apply for all the factors)."

\section{Summary of Assumptions}

In this paragraph will be presented a short summary of the previously mentioned assumptions of this study and whether they have been proved or not according to the analysis.

- People's behavior toward a charity case differs from the source they get the information from -Proved

- Trustworthiness toward source plays a big role in people's behavior - Proved

- Level of education influences people's decision whether to donate or not - Proved

- Age has a certain influence toward donating - Not proved.

- Having a full time job vs. not having it influences attitude toward donating - Proved

- Social network can also have some sort of social pressure in convincing people donate Proved

- The target group of this study, people living in Austria and Austrians, tend to not be willing to publically speak about their donation actions - Proved 


\section{Simulation Process}

Cluster Analysis (Two Step Cluster)

The final step of the analysis is the simulation process. As already explained above the simulation process is done in order to check if the information of the donation case percolates among the special community. In our study we want to test whether: "the information of donating about a specific case percolates among a group of friends/relatives".

The simulation itself happens in the LSD (Laboratory for Simulation Development) software ${ }^{2}$. The process is going to happen in a regular lattice. The lattice is 2 dimensional and each node/agent has exactly four neighbors to which it is connected to. This means that the node can get direct information only from these four neighbors.

It is needed to create a mathematical function in order to create our model which we are going to test in the program. The function will be designed with conditions and characteristics taken from the results of the above explained statistical analysis of the online questionnaire.

In order to create these conditions a cluster analysis is done to build different groups explaining the characteristics of different nodes/agents that will be placed in the lattice. In this way, the behavior and characteristics of the respondents will be used to build the structure of the lattice in the simulation program.

The basis on which the clusters are created, are the factors that are proved to have an influence in the people's behavior from the binary logistic regression.

- Trustworthiness (b)

- Education level (e)

- Extrinsic motivation ( $a, c, f)$

- Intrinsic motivation (d)

The analysis has created overall two clusters of respondents. One cluster contains $39.8 \%$ of the respondents and the other one contains $60.2 \%$ of the respondents. In this way also the nodes in the lattice will be divided in two clusters where the percentage of each is as shown in the cluster analysis.

In the first cluster (39.8\%) it is observed that only $42.8 \%$ of respondents answered that they would donate for the case when presented from a friend relative. In the second cluster $(60.2 \%)$ it is observed that $36.4 \%$ respondents answered that they would donate for the case when presented from a friend/relative.

These two clusters could be described in this way:

"Motivated Intellectuals" (First cluster) - From the cluster classification it is noticed that in this cluster belong the respondents who: have generally higher education; the intrinsic motivation and extrinsic motivation tend to be high.

"Indifferent people" (Second cluster) - From the cluster classification it is noticed that in this cluster belong the respondents who: have generally lower level of education and the intrinsic motivation and extrinsic motivation tends to be lower compared to the first cluster.

In this way, the first cluster would have a probability of 0.428 of adopting the innovation and the second cluster would have a probability of 0.364 of adopting the innovation.

These clusters have both their own characteristics. They are built using as a "cluster descriptor" the question "Would you donate if your close friend/relative gave you the information?"

The program describes this separation of respondents in 2 clusters as a fair classification quality (see Fig.2 Cluster Quality below). This makes our cluster analysis significant for further usage in our simulation process. 


\section{FIGURE 2 \\ CLUSTER ANALYSIS}

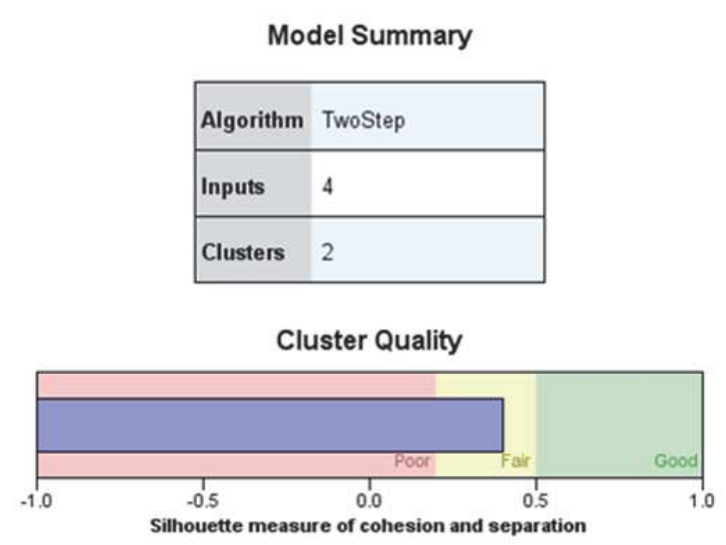

The Structure of the Simulation Model

The model should build conditions in which the nodes would adopt the donation theme presented by their neighbors. The simulation itself has several time steps. In this way, the state of the agents is defined by two main factors. One of them is the state of the neighboring agents in previous time steps. The other main factor is related to the probability that the agents have to adopt according to their characteristics developed from the statistical analysis of the online survey results.

The state of the neighboring agents in the previous time steps is one factor that should be assumed and set previously from the beginning. Since it is not based in the analysis, we will try two different options. In this way there will take place two simulation processes, where all the factors stay the same except of the time function.

Function of time $\mathrm{t}=1,2,3 \ldots$ ?

\section{Option I}

1 -Active cell

0 -Non-active cell

If $s(i ; t-1)=1$ than $t=1$ (for each time step)

If $\mathrm{s}(\mathrm{i} ; \mathrm{t}-1)=0$ then

$1: s(i ; t)=1$ if at least 2 of the neighbors $s(t-1)=1$

$2: s(i ; t)=0$ if 3 or more from 4 of the neighbors $s(t-1)=0$

In this way the cell gets active in the current time step if in the previous one at least 2 of the neighbors were active.

\section{Option II}

1 -Active cell

0 -Non-active cell

If $s(i ; t-1)=1$ than $t=1$ (for each time step)

If $\mathrm{s}(\mathrm{i} ; \mathrm{t}-1)=0$ then

$1: \mathrm{s}(\mathrm{i} ; \mathrm{t})=1$ if at least 1 of the neighbors $\mathrm{s}(\mathrm{t}-1)=1$

$2: s(i ; t)=0$ if 4 of the neighbors $s(t-1)=0$

In this way the cell gets active in the current time step if in the previous one at least 1 of the neighbors was active. 
Binary Logistic Regression

$(\log (p / p-1)=0.029+2.004 a+1.274 b+3.388 c+1.284 d+1.170 e+1.480 f$

The agents in the lattice are divided in 2 clusters.

Cluster " 1 " containing:

- $\quad 39.8 \%$ of the total number of cells.

- Each cell having 0.428 probability of adopting/becoming active.

Cluster " 2 " containing:

- $\quad 60.2 \%$ of the total number of cells.

- Each cell having 0.364 probability of adoption/becoming active.

\section{Results of the Simulation Process}

According to the mathematical function explained above we did the specific coding in the LSD program aiming to answer our main research question of the study:

"Will the social percolation model explain the behavior of potential donators in this specific social network?"

The simulation process resulted in this final lattice after making more than 1000 time steps.

- Simulation result (Option 1)

FIGURE 3

SIMULATION 1

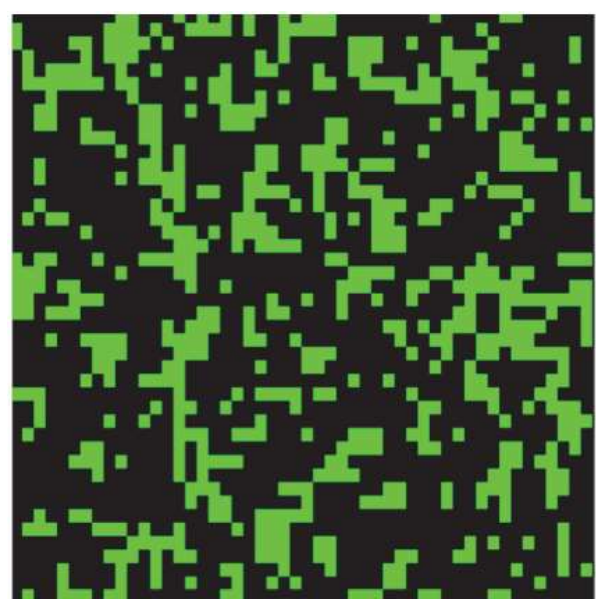

The simulation process is realized in a two dimensional $(50 \times 50)$ regular lattice. The percolation threshold to be passed in order to have an innovation is set to be 0,62 . Only $41 \%$ of the total number of cells were activated in the last/final simulation step. The green cells represent the activated cells, whereas the black cells represent the not activated cells.

$0.41<0.62-$ Percolation does now happen. 
-Simulation result (Option 2)

\section{FIGURE 4 SIMULATION 2}

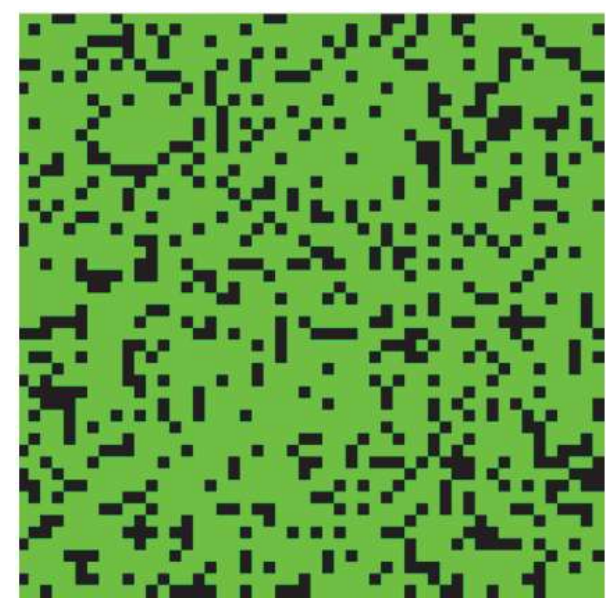

In the other simulation option it is noticed even from the picture itself the difference it has from the first one. The percolation threshold to be passed in order to have an innovation is set to be 0,62 . In this case from the results' analysis we can conclude that $93.34 \%$ of the cells were activated in the last simulation time step.

$0.93>0.62$ - Percolation happens. In this second simulation case we can say that percolation took place in our study.

As already explained, the difference in these two simulations is the assumption made for the time function. One of the factors defining the percolation is the state of the neighboring cells. In the first case "no percolation", each agent should have had at least 2 neighboring agents active in the previous time step in order to become active. In the second case "percolation", each agent should have had at least 1 neighboring agent active in the previous time step in order to become active. This number was the only one to create the huge difference between our two simulation processes, while where everything else remained the same.

As a conclusion, we can say that our main research question was answered positively. Social percolation explains the donation behavior of our special interest group. When a close friend/relative informs somebody about a donation case they have already donated, people tend to adopt this innovation and donate for the donation cause as well. This happens with the condition that people would adopt this donation cause even when only 1 close member of their social network asks them to do so.

\section{MANAGERIAL IMPLICATIONS}

This study tried to give a totally new perspective in the world of donations and charity in general. This is the first time that a donation process is trying to be explained by social percolation theory. Although it would require lots of more research in this new perspective to come up with highly significant results and implications, still there are some meaningful managerial implications deriving from this study that would definitely be worth of mentioning. Here some of them:

Consider the power of word of mouth in charity and fund raising.

First of all, one of the most important findings that would be mentioned as an advice for charity companies is: "considering more the power of word of mouth". This study confirmed that the power that 
word of mouth coming from our close people has, is sometimes higher than the power of the ways that charity companies usually use to attract donators. In this way generating WOM should be one of the priorities these kind of companies use when trying to raise funds for a donation cause.

- Identify the right group of people.

Another important implication is definitely the identification of the right target group who would be willing to spread the word about the specific donation case. This is considered to be challenging as much as it is considered to be helpful for raising funds. This is challenging because it is difficult for companies to have data describing qualities such as education level or willingness to publically speak about donations among their potential donators. One way would be having data about the people who are already registered as donators in the company. Once the company can identify somehow the best early adopters, the remaining part of the campaign would be way much easier.

- The need people have to feel socially acceptable.

One of the most important reasons why social percolation works in this context is absolutely the need people have to feel socially acceptable. It is highly important for people to feel that they are perceived as philanthropist or that they are part of a group who do humanitarian perceived actions. Logically, the more their social network is talking about a donation cause, the more people would want to join this actions as a way to feel better about themselves.

\section{LIMITATIONS}

To begin with, it is worth mentioning that social percolation was firstly used in this work in the context of charity and donation. Previous literature has a lot to do with the social percolation of innovations in new technologies and new products. Since everything was done for the first time in this context, there was an absence of theoretical background in building the model, the research design and everything else.

The scenarios of the study were simulated scenarios. This means that people were asked to imagine that they would be presented to such a case and then about the reaction they would have. If the experiment was not hypothetical, but consisting on observations of real behavior of potential donators, the results would be more meaningful. The effectivity of asking respondents to imagine any sort of real life situation is not that high.

The simulation process itself had its own limitations. The lattice were the simulation took place was a two dimensional regular lattice where each agent/node had exactly four direct neighbors. All the neighboring nodes had the exact same distance between each other. This means that the agents were perceived as all were having the same influence on others. In a more realistic situation different people/nodes would have different perceived influence in their friend/relatives/neighbors. For this kind of study there is needed a more specific technique in the simulation process which was exceeding the working level of a master thesis (the initial form of this article).

\section{FURTHER RESEARCH}

This is the starting point of studying the effectivity of word of mouth in donation networks in the perspective of social percolation. There are plenty of other studies that can be done in order to deepen the knowledge in this area of research.

It would be interesting to make a comparison between the behavior of people living in Austria and people living in countries where the culture and mentality toward charity is different and see how the percolation of information differs in these two target groups of people.

As previously mentioned, it would be more realistic to give different potential influence among their social environment to different nodes. This would help charity organization in picking the right target group of donators which would spread the word of donating about their causes in a more effective way. 
Another potential study would be testing the speed and frequency of donation made when potential donators are contacted directly from the company and when potential donators have gotten the information through word of mouth.

\section{ENDNOTES}

1. Binary choice is an assumption. Future research will consider fuzzy numbers instead of $0 / 1$ choices. The introduction of non- binary choices is classified as fuzzy percolation (Luzuriaga, Onaral, Banu \& Cammarota, 1999)

2. LSD is the software which is going to be used for the simulation process. It is a software which was created by Prof. Marco Valente, teaching in University of Aquila/Italy. The program creates simulations for different models, including here different percolation models.

\section{ACKNOWLEDGEMENT}

This work would not have been successfully finished without the crucial help of Mr. Marco Valente, Associate Professor of Economics at University of L'Aquila and Ms. Elisabeth Nyanda, Head of Donation Marketing at Doctors Without Borders, Austria.

\section{REFERENCES}

Bearden, W.O., \& Etzel, M J. (1982). Reference Group Influence on Product and Brand Purchase Decisions. Journal of Consumer Research, 9(2), 183ì. doi:10.1086/208911

Bearden, W.O., \& Rose, R.L. (1990). Attention to Social Comparison Information: An Individual Difference Factor Affecting Consumer Conformity. Journal of Consumer Research, 16(4), 461. doi:10.1086/209231

Bruyn, A.D., \& Lilien, G.L. (2008). A multi-stage model of word-of-mouth influence through viral marketing. International Journal of Research in Marketing, 25(3), 151-163. doi:10.1016/j.ijresmar.2004.03.004

Davis, F.D., Bagozzi, R.P., \& Warshaw, R.P. (1992). Extrinsic and Intrinsic Motivation to Use Computers in the Workplace. Journal of Applied Social Psychology, 22(14), 1111-32.

Delre, S.A., Jager, W., Bijmolt, T.H.A., \& Janssen, M.A. (2007). Targeting and timing promotional activities: An agent-based model for the takeoff of new products. Journal of Business Research, 60(8), 826-35.

Delre, S.A., Jager, W., \& Janssen, M.A. (2007, June). Diffusion dynamics in small-world networks with heterogeneous consumers. Computational and Mathematical Organization Theory, 13(2), 185 202

Delre, S.A., Jager, W., Tammo, H., Bijmolt, A., \& Janssen, M.A. (2010). Will It Spread or Not? The Effects of Social Influences and Network Topology on Innovation Diffusion. Journal of Product Innovation Management, 27(2), 267-82.

Delre, S.A., Jager, W., \& Janssen, M.A. (2009). The influence of network topology and social preference on diffusion processes.

Diffusion Definition in Chemistry (2018, September 23). Retrieved from https://www.thoughtco.com/search?q=diffusion

Dodds, P.S., \& Watts, D.J. (2005). A generalized model of social and biological contagion. Journal of Theoretical Biology, 232(4), 587-604.

Erlandsson, A., Västfjäll, D., Sundfelt, O., \& Slovic, P. (2016). Argument-inconsistency in charity appeals: Statistical information about the scope of the problem decrease helping toward a single identified victim but not helping toward many non-identified victims in a refugee crisis context. Journal of Economic Psychology, 56, 126-40. 
Goldenberg, J., Libai, B., Solomon, S., Jan, N., \& Stauffer, D. (2000). Marketing percolation. Physica A: Statistical Mechanics and its Applications, 284(1-4), 335-47.

Luzuriaga, Onaral, Banu, \& Cammarota, P. (1999). Fuzzy percolation model for loss of consciousness under acceleration stress. pp. 139-143.

Macy, M.W. (1991). Chains of Cooperation: Threshold Effects in Collective Action. American Sociological Review, 56(6), 730.

Mort, J. (1991). Perspective: The Applicability of Percolation Theory to Innovation. Journal of Product Innovation Management, 8(1), 32-38.

Rahmandad, Hazhir, \& Sterman, J. (2008). Heterogeneity and Network Structure in the Dynamics of Diffusion: Comparing Agent-Based and Differential Equation Models. SSRN Electronic Journal.

Rogers, E.M. (1993). The Diffusion of Innovations Model. Diffusion and Use of Geographic Information Technologies, 9-24. doi:10.1007/978-94-011-1771-5_2.

Silverberg, G., \& Verspagen, B. (2005). A percolation model of innovation in complex technology space. Journal of Economic Dynamics and Control, 29(1-2), 225-44.

Solomon, S., Weisbuch, G., De Arcangelis, L., Jan, N., \& Stauffer, D. (2000). Social percolation models. Physica A: Statistical Mechanics and its Applications, 277(1-2), 239-47. doi:10.1016/s03784371(99)00543-9.

Stauffer, D., Adler, J., \& Aharony, A. (1994). Universality at the three-dimensional percolation threshold. Journal of Physics A: Mathematical and General, 27(13).

Valente, T. W. (1996). Social network thresholds in the diffusion of innovations. Social Networks, 18(1), 69-89.

Venkatesh, V., Morris, M.G., Davis, G.B., \& Davis, F.D. (2003). User Acceptance of Information Technology: Toward a Unified View. MIS Quarterly 27.

Watts, D. J. (2002). A simple model of global cascades on random networks. Proceedings of the National Academy of Sciences, 99(9), 5766-71

Wierman, J.C. (1982). Percolation Theory. The Annals of Probability, 10(3), 509-24. 